\title{
PADRÕES ELETROFORÉTICOS DE CULTIVARES DE TRIGO INDICADAS PARA REGIÃO SUL DO BRASIL
}

\author{
ELECTROPHORETIC PATTERNS OF WHEAT CULTIVARS IN SOUTHERN BRAZIL
}

\author{
Elbio Treicha Cardoso ${ }^{1}$ Jorge Luiz Nedel ${ }^{2}$
}

\section{RESUMO}

\begin{abstract}
No Brasil, a identificação de cultivares envolve, na sua grande maioria, caracteres morfológicos de sementes, plântulas ou plantas. Os métodos que utilizam eletroforese permitem identificar estas cultivares com redução no tempo e a custos menores. Os objetivos deste trabalho foram definir o padrão eletroforético de cultivares de trigo indicadas para cultivo nos Estados da Região Sul do Brasil, bem como verificar a variação intra-cultivar destes genótipos. Foram empregados quatro sistemas de eletroforese, dois utilizando proteina total (APAGE e SDS-PAGE) e dois sistemas isoenzimáticos (esterase $e$ peroxidase). $O$ sistema APAGE permitiu identificar individualmente as cultivares $B R \quad 18, B R$ 35, CEP 24, CEP 27, EMBRAPA 15, EMBRAPA 40, IAPAR 17, IAPAR 29, OCEPAR 16, OCEPAR 21, RS O1e RS O8 e reunir as demais em três grupos: grupo 1: BR 38 e EMBRAPA 52; grupo 2: EMBRAPA 16, EMBRAPA 24 e EMBRAPA 49; grupo 3: BR 23, BR 32 e IAPAR 28. Com a utilização do SDS-PAGE e da isoenzima esterase, foi possível individualizar as cultivares dentro dos grupos. Variação intra-cultivar utilizando APAGE não foi detectada. A cultivar EMBRAPA 16 apresentou variação no sistema em SDS-PAGE. Através da isoenzima esterase, foi detectada variação dentro das cultivares BR 38 e EMBRAPA 15 e com a peroxidase nas cultivares BR 23, CEP 24, CEP 27, EMBRAPA 15, EMBRAPA 40 e IAPAR 17. Os resultados obtidos neste trabalho indicam que é possível caracterizar cultivares de trigo utilizando eletroforese, desde que os sistemas sejam empregados de modo combinado.
\end{abstract}

Palavras-chave: Triticum aestivum, caracterização, eletroforese.

\section{SUMMARY}

In Brazil, the methods traditionally used for cultivar identification are morphologic traits from seed, seedling or plant. The methods using electrophoresis allows cultivar identification using less time and resources. The objectives of this study was to define the electrophoretic pattern of wheat cultivars in Southern Brazil, as well as to verify intra-cultivar variation. Four electrophoresis systems were used in polyacrylamide gels. Two were used for total protein (APAGE and SDS-PAGE) and two for the enzymatic systems of esterase and peroxidase. The APAGE allowed to characterize individually the cultivars $B R 18, B R 35$, CEP 24, CEP 27, EMBRAPA 15, EMBRAPA 40, IAPAR 17, IAPAR 29, OCEPAR 16, OCEPAR 21, RS 01 and RS 08 and put the others in to three groups: group 1: BR 38 and EMBRAPA 52; group 2: EMBRAPA 16, EMBRAPA 24 and EMBRAPA 49; group 3: BR 23, BR 32 and IAPAR 28. With the utilization of SDS$P A G E$ and esterase it was possible to individualize the cultivars of the three groups. Intra-cultivar variation were not detected using APAGE. However, EMBRAPA 16 showed variation in SDS$P A G E$. Using esterase, intra-cultivar variation was detected in BR 38 and EMBRAPA 15; for peroxidase intra-cultivar variation was detected in BR 23, CEP24, CEP 27, EMBRAPA 15, EMBRAPA 40 and IAPAR 17. The results showed that it is possible to identify wheat cultivars by electrophoresis, since the different systems are combined.

Key words: Triticum aestivum, characterization, electrophoresis.

\section{INTRODUÇÃO}

Caracterizar e/ou identificar uma cultivar é importante por várias razões, dentre as quais se pode enumerar o desejo do agricultor de utilizar as mais adaptadas e produtivas, o interesse da entidade certificadora e fiscalizadora, bem como da indústria de sementes em assegurar a produção de sementes de alta qualidade; a necessidade do melhorista e/ou da empresa de melhoramento em garantir o retorno do seu investimento na pesquisa e desenvolvimento de novos genótipos.

No Brasil, os métodos tradicionalmente utilizados para identificação variam de espécie para espécie e envolvem, na sua maioria, caracteres da

\footnotetext{
${ }^{1}$ Engenheiro Agrônomo, Mestre; Doutorando no Curso de Pós-graduação em Fitotecnia, Faculdade de Agronomia, Departamento de Plantas de Lavoura, Universidade Federal do Rio Grande do Sul (UFRGS). Bolsista do CNPq. Av. Bento Gonçalves, 7712, 91540-000, Porto Alegre, RS. E-mail:elbio@vortex.ufrgs.br. Autor para correspondência.

${ }^{2}$ Engenheiro Agrônomo, PhD., Professor Titular, Departamento de Fitotecnia, Faculdade de Agronomia Eliseu Maciel, Universidade Federal de Pelotas, Bolsista do CNPq. E-mail: jlnedel@ufpel.tche.br.
} 
morfologia de semente, plântula e/ou planta. Contudo, com o lançamento contínuo de novas cultivares, estes caracteres empregados na diferenciação mostram-se insuficientes para identificar todos os genótipos. Diante disso, MCDONALD (1984 e 1988) afirmou que os testes baseados em caracteres morfológicos não eram precisos. Isto porque o armazenamento e o ambiente a que os genótipos são submetidos podem mascarar caracteres morfológicos específicos, dificultando e ou impossibilitando a identificação. Nestes mesmos trabalhos, o autor relacionou uma série de características negativas das avaliações morfológicas, em laboratório e a campo, na identificação varietal.

Estes aspectos negativos levaram as entidades que trabalham na certificação de sementes a buscarem outros métodos, alterando o enfoque de caracteres morfológicos para bioquímicos, na busca de complementar as deficiências atualmente reconhecidas. Dentre as principais características buscadas nestes novos métodos, estão a rapidez e a segurança nos resultados, simplicidade nas avaliações e baixo custo.

As proteínas são produtos diretos dos genes, sendo, portanto, possível admiti-las como marcadores dos genes que as codificam. A proximidade neste processo entre proteína sintetizada e a informação genética primária (DNA), reduz ou, em alguns casos, elimina os efeitos ambientais permitindo que a confrontação do polimorfismo protéico entre cultivares seja considerado como comparação entre diferentes constituições genéticas (COOKE, 1995). Na avaliação da constituição protéica de plantas, é reportada ampla utilização de métodos que utilizam eletroforese, com resultados positivos para as mais diversas espécies, como milho (STUBER et al., 1988), soja (MCDONALD, 1991), aveia, (MCDONALD, 1980) e festuca (KRISHNAN \& SLEPER, 1997). Na cultura do trigo, sistemas a base de poliacrilamida em meio ácido (APAGE) foram descritos por BUSHUK \& ZILLMAN (1978) e VAN DE WEGHE (1991). Sistemas utilizando dodecil sulfato de sódio com acrilamida (SDSPAGE), foram descritos por FULLINGTON $\boldsymbol{e t} \boldsymbol{a l}$. (1983) e COOKE (1992). O emprego de sistemas isoenzimáticos foi descrito por COOKE (1986).

O presente trabalho teve por objetivo definir e comparar os padrões apresentados por cultivares de trigo indicadas para cultivo no Rio Grande do Sul, Santa Catarina e Paraná em 1996, para as isoenzimas esterase e peroxidase, e proteína total em condições naturais (APAGE) e condições de dissociação (SDS-PAGE), bem como verificar a variação intra-cultivar para estes sistemas .

\section{MATERIAL E MÉTODOS}

\section{Extração das proteínas e isoenzimas para eletroforese}

Semente genética das cultivares de trigo BR 18, BR 23, BR 32, BR 35, BR 38, CEP 24, CEP 27, EMBRAPA 15, EMBRAPA 16, EMBRAPA 24 , EMBRAPA 40, EMBRAPA 49, EMBRAPA 52, IAPAR 17, IAPAR 28, IAPAR 29, OCEPAR 16, OCEPAR 21, RS 01 e RS 08 foram semeadas em parcelas isoladas e, quando da maturação, colheu-se a espiga do colmo principal de 20 plantas de cada cultivar.

Para eletroforese entre cultivares, utilizou-se uma semente de cada cultivar e duas repetições. Para avaliação intra-cultivar, foi realizado um gel para cada cultivar nos quatro sistemas, utilizando-se 18 amostras originadas de espigas diferentes.

Para APAGE, o procedimento de extração foi moer individualmente as sementes e extrair as proteínas utilizando uma solução de uréia $6 \%$ (adaptado de RACI, 1988) numa relação de 1:6 (peso/volume) por aproximadamente 16 horas. Após, as amostras foram centrifugadas a 14.000rpm por 5 minutos e $15 \mu \ell$ (microlitros) do sobrenadante aplicados na parte superior do gel.

No sistema de SDS-PAGE, a extração foi realizada moendo-se as sementes individualmente e misturando-as durante uma hora com a solução aquosa de extração $(0,063 \mathrm{M}$ de TRIS com pH 6,8, $10 \%$ de glicerol, $2,0 \%$ de SDS, $5 \%$ mercaptoetanol ), numa relação de 1: 8 (peso/ volume). Após uma hora, a mistura foi aquecida em banho-maria, com água fervente, por 10 minutos e centrifugada. Aplicou-se $5 \mu \ell$ do sobrenadante no gel superior.

$\mathrm{O}$ procedimento de extração das isoenzimas consistiu em germinar sementes de cada espiga, em rolo de papel, à temperatura de $20^{\circ} \mathrm{C}$ por 5 dias. Após o quinto dia, as plântulas foram maceradas em separado e colocadas na solução extratora (Acetato de Sódio 0,1M pH 8,0) numa relação 1:3 (peso/volume) conforme descrito por Payne (1985), durante uma hora em baixa temperatura. Procedeu-se a centrifugação e aplicouse $25 \mu \ell$ do sobrenadante no gel superior.

\section{Sistemas de eletroforese}

APAGE em pH 3,2 - Método padrão da International Seed Testing Association (ISTA), modificado por VAN DE WEGHE (1991). 
As soluções tampões do gel e do tanque foram preparados dissolvendo respectivamente 1,0 e $0,4 \mathrm{~g}$ de glicina em água destilada, adicionando-se ácido acético glacial até atingir $\mathrm{pH} 3,2$ e água destilada até o volume final de 11 da solução (VAN DE WEGHE, 1991).

$\mathrm{Na}$ sua composição, o gel possuiu acrilamida na concentração de $6,5 \%$, uréia $6 \%$ e bisacrilamida $0,4 \%$ conforme descrito por VAN DE WEGHE (1991). A separação das proteínas foi realizada com polaridade invertida na fonte de eletroforese utilizando-se a voltagem constante de $250 \mathrm{~V}$ até o corante verde de metila atingir o fim do gel.

A revelação das bandas protéicas foi realizada mergulhando-se o gel numa solução de $90 \mathrm{~m} \ell$ de Ácido Tricloroacético $10 \%$ mais $10 \mathrm{~m} \ell$ de Azul de Comassina R250 1\% em etanol conforme o descrito na ISTA (1993).

SDS-PAGE Método padrão da ISTA (1993).

A solução tampão do tanque foi preparada com 3,0g de TRIS, 14,1g de glicina, 1,0g de SDS, tudo dissolvido em água e completado o volume final de 11 . As soluções tampões dos géis inferior e superior foram de TRIS $1 \mathrm{M}$ com pH de 8,8 e 6,8 respectivamente.

O gel inferior ou de separação teve concentração de acrilamida de $13 \%$, bisacrilamida $0,17 \%$ e SDS $1 \%$ e o gel superior ou de empilhamento teve a concentração de acrilamida de $6 \%$, bisacrilamida $0,10 \%$ e SDS $0,12 \%$.

A separação das proteínas foi realizada com polaridade normal, sob corrente constante de $25 \mathrm{~mA} /$ placa de gel. Considerou-se terminada a corrida quando o corante azul de bromofenol chegou próximo ao final do gel inferior.

Para revelação, deixou-se o gel inferior ou de separação por uma hora na solução de fixação (metanol - ácido acético - água numa relação de 4:1:5 em volume). Após este período, o gel foi colocado na solução reveladora $(95 \mathrm{~m} \ell$ de Ácido Tricloroacético $15 \%$ em água $+5 \mathrm{~m} \ell$ de Azul de Comassina $0,5 \%$ em metanol).

Isoenzimas ( Peroxidase e Esterase) - Método padrão da Association of Official Seed Analyst (AOSA, 1991).

A solução tampão do tanque superior foi preparada dissolvendo 3,0g de TRIS e 14,4g de glicina em água destilada e completado o volume para 11 . No preparo da solução do tanque inferior, diluiram-se $350 \mathrm{~m} \ell$ da solução do tanque superior em água destilada até completar 11 (AOSA, 1991).
A solução tampão do gel inferior foi preparada com TRIS $3 \mathrm{M}$ em pH de 8,8 e a do gel superior TRIS $0,5 \mathrm{M}$ com pH 6,8. O gel de separação tem a concentração de acrilamida de $7 \%$ e bisacrilamida de $0,18 \%$, enquanto o gel superior possui uma composição diferenciada apresentando acrilamida na concentração de $3,3 \%$, bisacrilamida $0,42 \%$, sacarose $17,8 \%$, e riboflavina $0,0005 \%$ (AOSA, 1991).

A separação das isoenzimas foi conduzida com polaridade normal e corrente constante de $35 \mathrm{~mA} /$ placa de gel, até o azul de bromofenol atingir o final do gel inferior. A revelação da isoenzima peroxidase foi realizada mergulhando o gel por 10 minutos numa solução de guaiacol $0,5 \%$, após numa solução de peróxido de hidrogênio $0,1 \%$ por 10 minutos e por último numa solução de ácido acético glacial $7 \%$ até o aparecimento das bandas de acordo com o procedimento descrito pela AOSA (1991). A isoenzima esterase foi revelada incubando o gel por 30 minutos no escuro, numa solução contendo 100 mg de Fast Blue RR, 3,0m $\ell$ da solução substrato $(\alpha-$ naphtil acetato $1 \%$ em acetona $50 \%$ ) e $100 \mathrm{~m} \ell$ de TRIS 0,05M pH 7,1 (ALFENAS ,1991).

Os sistemas de eletroforese aqui descritos foram utilizados em cubas verticais e neste trabalho foram utilizadas placas de eletroforese com dimensões de $130 \mathrm{~mm}$ de altura e $165 \mathrm{~mm}$ de largura com espaçadores de $1 \mathrm{~mm}$ de espessura.

\section{Características avaliadas nos géis}

Mobilidade Relativa(MR) - Os valores de mobilidade relativa foram calculados para todas as cultivares tendo como referência a primeira banda da cultivar EMBRAPA 52, à qual foi arbitrado o valor de 15\%, (adaptado de BUSHUK \& ZILLMAN, 1978). Para o cálculo das demais bandas, utilizou-se a seguinte formula $\left(\mathrm{d}^{*} 15\right) / \mathrm{D}$, onde d é a distância em milímetros percorrida pela banda no gel, 15 mobilidade relativa arbitrada para primeira banda da cultivar EMBRAPA 52 e D distância em milímetros percorrida pela banda tomada como referência. Esta banda foi escolhida porque é facilmente observada no gel e esteve presente em todos os géis.

Para as isoenzimas, o cálculo da mobilidade relativa foi realizado pela relação entre a distância percorrida no gel pelas bandas de cada cultivar e a distância percorrida pelo marcador azul de bromofenol, de acordo com o descrito por PAYNE (1985).

A utilização da metodologia de MR permite relacionar a mobilidade das bandas de cada 
cultivar com um padrão. Isto possibilita que o mesmo procedimento possa ser realizado em outros laboratórios com os seus resultados reprodutíveis e comparáveis.

\section{RESULTADOS E DISCUSSÃO}

Comparando-se os padrões eletroforéticos das cultivares avaliadas pelo sistema de APAGE, observa-se que as mobilidades relativas variam de 13 a $80 \%$ e que na região de bandas com maior mobilidade, 59 a $80 \%$, todas apresentam o mesmo padrão (Tabela 1).

Com base nesse padrão de mobilidade, foi possível individualizar as cultivares BR 18, BR 35, CEP 24, CEP 27, EMBRAPA 15, EMBRAPA 40, IAPAR 17, IAPAR 29, OCEPAR 16, OCEPAR 21, RS 01 e RS 08. As demais foram reunidas em três grupos: grupo 1: BR 38 e EMBRAPA 52; grupo 2: EMBRAPA 16, EMBRAPA 24 e EMBRAPA 49; grupo 3: BR 23, BR 32 e IAPAR 28.

Os resultados de mobilidade relativa da isoenzima esterase, apresentados na tabela 2, permitem individualizar as cultivares BR 38, CEP 24, CEP 27 e OCEPAR 21; e reunir as demais em quatro grupos: grupo 1: BR 32, EMBRAPA 24, EMBRAPA 40, EMBRAPA 49, IAPAR 17 e RS 01; grupo 2 : BR 35, EMBRAPA 52, IAPAR 29 e OCEPAR 16; grupo 3 : BR 18, BR 23, EMBRAPA 15 e EMBRAPA 16; grupo 4: IAPAR 28 e RS 08.

Os agrupamentos obtidos anteriormente, através de APAGE e esterase, sugerem a existência de relações de parentesco dentro dos grupos. No entanto, pelo estudo da genealogia das cultivares, apresentada na tabela 3 , isso não foi confirmado. Dentro dos grupos formados em APAGE foi identificado um genitor comum as cultivares BR 23 e BR 32 e nos agrupamentos obtidos com a isoenzima esterase as cultivares BR 18 e BR 23 apresentaram também um pai em comum. O genótipo presente na genealogia das três cultivares é o ALONDRA SIB, o qual, segundo SOUSA (1997), é um dos progenitores mais utilizados no melhoramento da cultura do trigo no Brasil.

$\mathrm{Na}$ avaliação conjunta dos resultados de APAGE e esterase, diferenciou-se a grande maioria das cultivares. A exceção foram as cultivares EMBRAPA 24 e EMBRAPA 49, as quais apresentaram padrões eletroforéticos idênticos, sendo necessária, então, a comparação pelos demais sistemas.

Não foi detectada diferença entre as cultivares com o uso da isoenzima peroxidase. A utilização do sistema de SDS-PAGE possibilitou a distinção entre os padrões eletroforéticos, na região de bandas com alto peso molecular, o que permitiu a identificação dos genótipos EMBRAPA 24 e EMBRAPA 49.

Os resultados obtidos neste trabalho são comparáveis aos de ANJUM, et al. (2000). Estes autores utilizaram o sistema APAGE em trigos paquistaneses, obtendo padrões únicos para a maioria e reunindo os demais em grupos, dentro dos quais não foram detectadas diferenças. Nesta mesma linha de trabalho, VAN DE WEGHE (1991) avaliou cultivares européias de trigo e triticale por meio de diferentes sistemas, baseados em proteína total, conseguindo a identificação de todas as cultivares. Contudo, à semelhança do realizado neste trabalho, o autor necessitou combinar as informações obtidas em cada um dos sistemas por ele empregados.

$\mathrm{Na}$ análise da variação intra-cultivar (Tabela 4), em APAGE, as cultivares não apresentaram variação detectável quanto a presença ou

Tabela 1 - Padrões eletroforéticos de Mobilidade Relativa (MR) apresentado pelas cultivares pelo sistema APAGE. Pelotas, 1997.

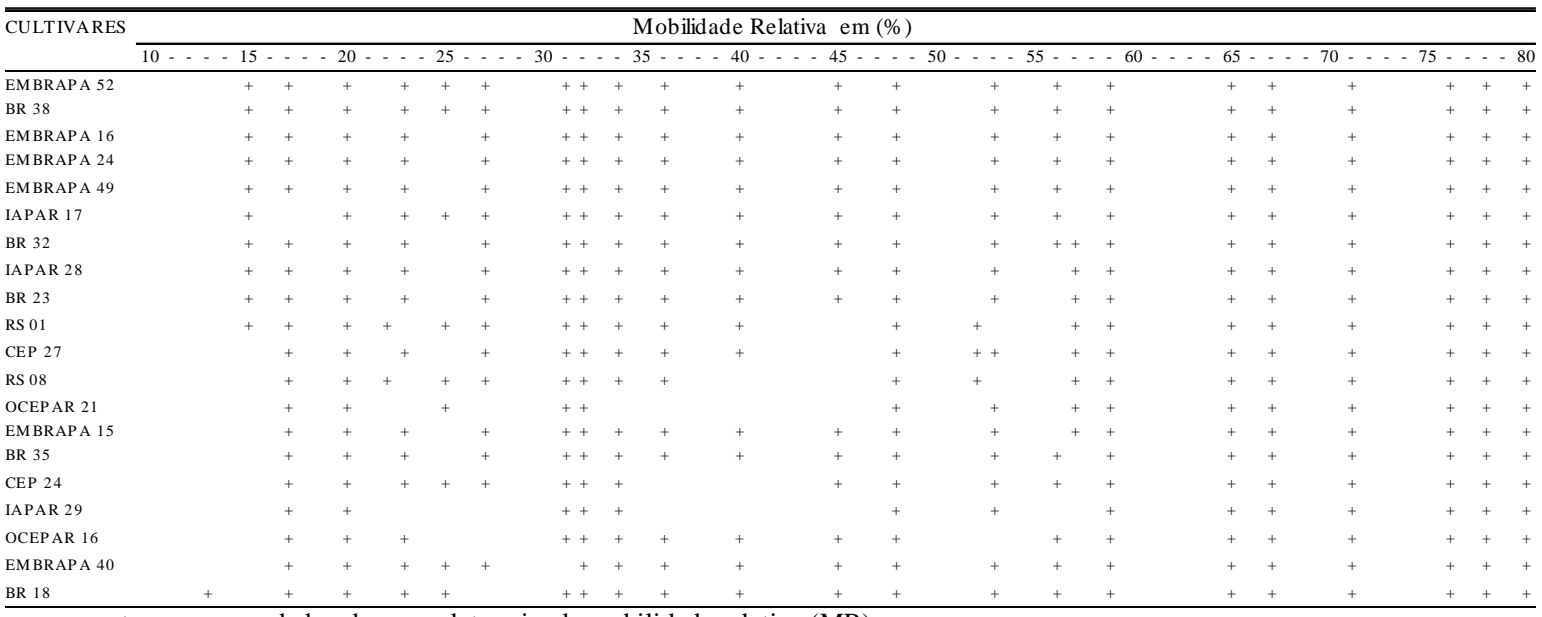

+ representa a presença de bandas com determinada mobilidade relativa (MR). 
Tabela 2 - Padrões eletroforéticos de Mobilidade Relativa (MR) apresentado pelas cultivares para isoenzima esterase Pelotas, 1997.

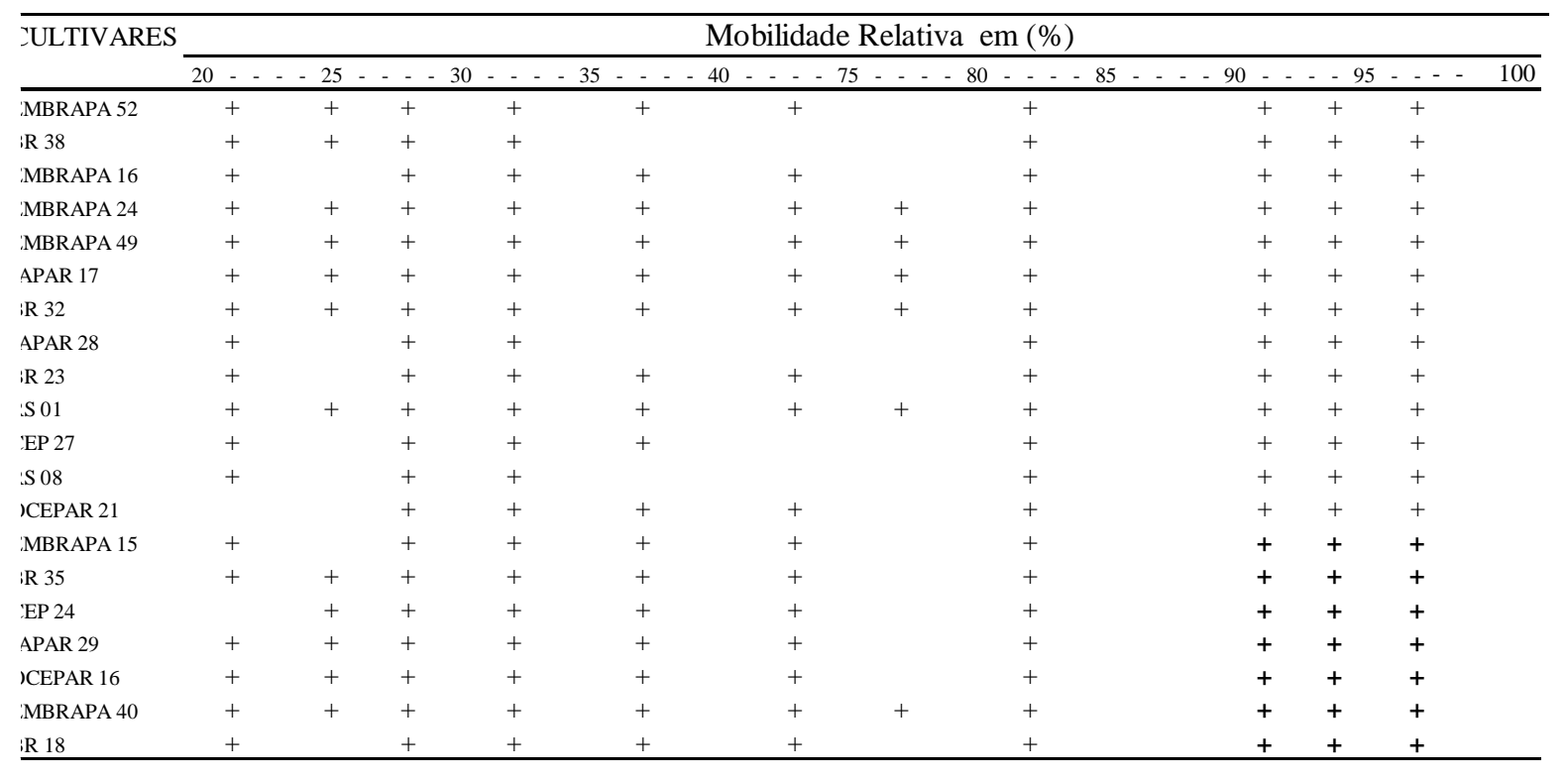

+ representam a presença de bandas com determinada mobilidade relativa (MR).

Tabela 3 - Genealogia das cultivares utilizadas na caracterização. Pelotas, 1997.

\begin{tabular}{ll}
\hline Cultivar & Genealogia \\
\hline BR 18 & D 6301/NAINARI 60//WEIQUE/RED MACE/3/CIANO*2/CHRIS,ALD SIB \\
BR 23 & CORRE CAMINOS/ ALONDRA SIB/3/IAS 54-20/COTIPORA//CNT 8 \\
BR 32 & IAS 60//INDUS//IAS 62/3/ALONDRA SIB/4/IAS 59 \\
BR 35 & IAC 5*2/3/CNT 7*3/LONDRINA//IAC 5/HADDEN \\
BR 38 & IAS 55*4/AGENT//IAS 55*4/CI 14123 \\
CEP 24 & BR 3/CEP 7887//CEP 7775/CEP 11 \\
CEP 27 & CEP 8057/BUTUI//CEP 8324 \\
EMBRAPA 15 & CNT 10/*BR 5//PF75172/TIFTON 72-59 SEL \\
EMBRAPA 16 & HULHA NEGRA/CNT 7//AMIGO/CNT 7 \\
EMBRAPA 24 & TIFTON72-59 SEL/PF 79763/3/NOBEOKA BOZU/3*LD//B 7908 \\
EMBRAPA 40 & PF 7650/NS 18-78//CNT 8/PF 7577 \\
EMBRAPA 49 & BR 35/PF 83619//PF 858/PF 8550 \\
EMBRAPA 52 & HULHA NEGRA/CNT 7//AMIGO/CNT 7 \\
IAPAR 17 & JUPATECO 73/BLUE JAY SIB \\
IAPAR 28 & KAVKAZ/BUHO SIB//KALYAN/BLUE BIRD, VEERY3, GENARO F81 \\
IAPAR 29 & BLUE JAY SIB/JUPATECO 73, OPATA 85 \\
OCEPAR 16 & SISKIN SIB/VEERY SIB \\
OCEPAR 21 & CEP 11/4/KALYAN/BLUE BIRD//CAJEME SIB/3/ALONDRA SIB \\
RS 01 & PF 70100/J 15157-69 \\
RS 08 & CNT 10/BURGAS 2 //JACUI \\
\hline
\end{tabular}

amostras destas cultivares. Esta variação pode ser uma característica da cultivar ou um caso de baixa concentração da isoenzima presente nas amostras, no qual não houve a detecção da atividade pelo método de análise utilizado. Para peroxidase, as cultivares BR 23, CEP 24, CEP 27, EMBRAPA 15, EMBRAPA 40 e IAPAR 17 apresentaram variação, pelo aparecimento de bandas que não estavam presentes na maioria das amostras destas cultivares (Tabela 4). Esta ocorrência não permite que a hipótese de baixa concentração seja levantada, porque além das bandas presentes na maioria ocorreu o surgimento de novas, demonstrando a variação das cultivares quanto ao padrão eletroforético apresentado pela isoenzima.

Os resultados para variação intra-cultivar utilizando SDS-PAGE, obtidos neste trabalho, diferem dos obtidos por ALMEIDA \& MOLINA (2000) em cevada. Estes autores detectaram polimorfismo em 12 das 14 variedades de cevada, enquanto neste sistema de eletroforese apenas a cultivar EMBRAPA 16 apresentou variação intra-cultivar. Uma explicação plausível para estas diferenças entre os resultados é a

Ciência Rural, v. 32, n. 2, 2002. 
Tabela 4 - Porcentagem de amostras e número de bandas (entre parênteses) de cada cultivar, apresentado nos quatro sistemas em estudo. Pelotas, 1997.

\begin{tabular}{|c|c|c|c|c|c|c|c|c|}
\hline \multirow[t]{2}{*}{ Cultivar } & \multirow[t]{2}{*}{ APAGE } & \multicolumn{3}{|c|}{ SDS-PAGE * } & \multicolumn{2}{|c|}{ Esterase } & \multicolumn{2}{|c|}{ Peroxidase } \\
\hline & & Alto PM & Médio PM & Baixo PM & & & & \\
\hline BR 18 & $100(21)$ & 100 & 100 & 100 & $100(9)$ & & $100(1)$ & \\
\hline BR 23 & $100(21)$ & 100 & 100 & 100 & $100(9)$ & & $86(1)$ & $14(2)$ \\
\hline BR 32 & $100(21)$ & 100 & 100 & 100 & $100(11)$ & & $100(1)$ & \\
\hline BR 35 & $100(20)$ & 100 & 100 & 100 & $100(10)$ & & $100(1)$ & \\
\hline BR 38 & $100(22)$ & 100 & 100 & 100 & $93(8)$ & $7(7)$ & $100(1)$ & \\
\hline CEP 24 & $100(19)$ & 100 & 100 & 100 & $100(9)$ & & $79(1)$ & $21(2)$ \\
\hline CEP 27 & $100(19)$ & 100 & 100 & 100 & $100(8)$ & & $79(1)$ & $21(2)$ \\
\hline EMBRAPA 15 & $100(20)$ & 100 & 100 & 100 & $79(9)$ & $21(8)$ & $93(1)$ & $7(2)$ \\
\hline EMBRAPA 16 & $100(21)$ & 93 & 100 & 100 & $100(9)$ & & $100(1)$ & \\
\hline EMBRAPA 24 & $100(21)$ & 100 & 100 & 100 & $100(11)$ & & $100(1)$ & \\
\hline EMBRAPA 40 & $100(20)$ & 100 & 100 & 100 & $100(11)$ & & $79(1)$ & $21(2)$ \\
\hline EMBRAPA 49 & $100(21)$ & 100 & 100 & 100 & $100(11)$ & & $100(1)$ & \\
\hline EMBRAPA 52 & $100(22)$ & 100 & 100 & 100 & $100(10)$ & & $100(1)$ & \\
\hline IAPAR 17 & $100(21)$ & 100 & 100 & 100 & $100(11)$ & & $79(1)$ & $21(2)$ \\
\hline IAPAR 28 & $100(21)$ & 100 & 100 & 100 & $100(7)$ & & $100(1)$ & \\
\hline IAPAR 29 & $100(14)$ & 100 & 100 & 100 & $100(10)$ & & $100(1)$ & \\
\hline OCEPAR 16 & $100(18)$ & 100 & 100 & 100 & $100(10)$ & & $100(1)$ & \\
\hline OCEPAR 21 & $100(15)$ & 100 & 100 & 100 & $100(8)$ & & $100(1)$ & \\
\hline RS 01 & $100(20)$ & 100 & 100 & 100 & $100(11)$ & & $100(1)$ & \\
\hline RS 08 & $100(19)$ & 100 & 100 & 100 & $100(7)$ & & $100(1)$ & \\
\hline
\end{tabular}

* SDS-PAGE não é apresentado o número de bandas devido a grande quantidade detectada, em cada cultivar, por este método.

utilização de pressão de seleção distintas em trigo e cevada, as quais permitiram a uniformização do comportamento das cultivares de trigo, não ocorrendo o mesmo em cevada.

A análise dos sistemas de eletroforese empregados neste trabalho permite afirmar que a isoenzima peroxidase apresenta restrições, as quais não recomendam o seu uso na identificação varietal. Estas limitações são o pequeno número de bandas detectadas, maioria das cultivares apenas uma, e a variação intra-cultivar a qual implica dificuldades adicionais na comparação dos padrões eletroforéticos obtidos, porque requer a utilização de um número maior de amostras. $\mathrm{O}$ uso da isoenzima esterase permitiu aos autores encontrar diferenças entre algumas cultivares, entretanto, em função do número de bandas visualizadas, no máximo 11, não foi possível a identificação de todos os genótipos.

A comparação dos resultados obtidos pelos sistemas APAGE e SDS-PAGE mostra que o sistema utilizando SDS-PAGE resulta no aparecimento de um grande número de bandas e permite a diferenciação das cultivares. Contudo, este grande número de bandas, e todas muito próximas, implica um grau de dificuldade bastante elevado na avaliação dos géis e comparação dos padrões obtidos. Esta maior complexidade restringe a adoção deste sistema como um procedimento rotineiro na identificação varietal, além do que há outras desvantagens comparativas que são maior custo e dificuldade de execução. Como regra geral para a identificação de cultivares, utilizando eletroforese, é recomendável que primeiro o estudo seja realizado com o sistema APAGE e que se utilizem os demais, como esterase e SDSPAGE, apenas nas amostras que não apresentaram diferenças detectáveis pelo primeiro. Isto porque o sistema com proteína total em condições naturais tem menor custo e maior simplicidade de execução, se comparado aos demais sistemas.

\section{CONCLUSÕES}

Os padrões eletroforéticos de proteínas obtidos pelos sistemas APAGE, isoenzima esterase e SDS-PAGE permitem diferenciar as cultivares de trigo indicadas para cultivo no Rio Grande do Sul, Santa Catarina e Paraná em 1996.

As cultivares de trigo, BR 23, BR 38, IAPAR 17, CEP 24, CEP 27, EMBRAPA 15, EMBRAPA 16 e EMBRAPA 40 apresentaram variação intra-cultivar.

\section{REFERÊNCIAS BIBLIOGRÁFICAS}

ALFENAS, A.C. Eletroforese de proteínas e isoenzimas de fungos e essências florestais. Viçosa : Universitária, 1991, 242 .

ALMEIDA, C.E., MOLINA, S.,C. Hordein variation in Brazilian barley varieties (Hordeum vulgare L.) and wild barley $(\mathrm{H}$. euclaston Steud. and H. stenostachys Godr.) Genetics and Molecular Biology, Ribeirão Preto, v.23, n.2, p.425-433, 2000 .

ANJUM, F. M., LOOKHART, G.L., WALKER, C.E., Electrophoretic identification of hard white spring wheats grown at different locations in Pakistan in different years. Journal of the Science of Food and Agriculture, Sussex, v.80, p.1155-1161, 2000.

ASSOCIATION OF OFFICIAL SEED ANALYSTS (AOSA). Cultivar purity testing handbook. Lincoln, 1991. p.1-60. 
BUSHUK, W., ZILLMAN, R.R. Wheat cultivar identification by gliadin electrophoregrams. I. apparatus, method and nomenclature. Canadian J Plant Sci, Ottawa, v.58, p.505515,1978 .

COOKE, R.J. The reasons for variety identification. In: WRINGLEY, C.W. Identification of food grain varieties. St. Paul : Congress, 1995. p.1-17.

COOKE, R.J. Handbook of variety testing. Zurique : International seed testing association, Electrophoresis handbook: Variety identification, 1992. p.33-58.

COOKE, R.J., SMITH, T.M., AINSWORTH, C.C. Discrimination between bread wheat, durum wheat, rye and triticale by electrophoresis of seed protein and enzymes. Seed Science and Technology, Zurique, v.14, p.693-704, 1986.

FULLINGTON, E.G., COLE, E.W., KASARDA, D.D., Quantitative sodium dodecil sulfate-polyacrylamide gel electrophoresis of total protein extracted from different cultivars. effect of protein content. Cereal Chemistry st. Paul, v.30, n.1, p.65-71, 1983.

INTERNATIONAL SEED TESTING ASSOCIATION (ISTA). International rules for seed testing, Seed Science and Technology, Zurique, v.21, p.217- 228, 1993.

KRISHNAN, H.B., SLEPER,D.A. Identification of tall fescue cultivars by sodium dodecil sulfate polyacrylamide gel electrophoresis of seed proteins. Crop Science, .Madison, v.37, p.215-219, 1997.

MCDONALD, M.B.Jr. Blotting of seed protein from isoelectricall, focused gels for cultivar identification. Seed Science and Technology, Zurique, v.19, p.33-40, 1991
MCDONALD, M.B.Jr. Oat cultivar characterization using electrophoresis. Journal of Seed Technology, Lincoln , v.5, p.88-101, 1980 .

MCDONALD, M.B. Jr. Challenges in seed technology. In: ANNUAL SEED TECHNOLOGY CONFERENCE, 1988 Procedure... Ames : Iowa State University, 1988. p.11-32.

MCDONALD, M.B. Jr. System for crop variety identification. In: SHORT COURSE FOR SEEDSMEN, 1984. Procedure... Mississipi State : Mississipi State University, 1984. v.26, p.31-53.

PAYNE, R.C. Electrophoresis testing procedure used by Federal Seed Laboratory to help distinghish varieties. Federal Seed Laboratory Bullettin, Lincoln, 20p. 1985.

ROYAL AUSTRALIAN CHEMICAL INSTITUTE. Official testing methods of the cereal chemical division. Melbourne, 1988. Electrophoretic identification of cereal varieties: p.24-27.

SOUSA, C.N.A. Relação das cultivares comerciais de trigo no Brasil de 1922 a 1997. Passo Fundo : EMBRAPA-CNTP, 1997. 46 p. (Documentos, 39).

STUBER,C.W., WENDEL, J.F., GOODMAN, M.M., et al., Techniques and scoring procedures for starch gel electrophoresis of enzymes from maize. North Carolina Agriculture Research Technical Bullettin, Raleigh, v.286, p.1-87, 1988.

VAN DE VEGHE, L. Comparative study of electrophoretic methods for cultivar identification of wheat and triticale. Seed Science and Technology, Zurique, v.19, p.41-50, 1991. 